\title{
Chemically-induced geometrical isomerization of stilbenes during peroxyoxalate chemiluminescence reaction: revisit to "photochemistry without light"
}

Jiro Motoyoshiya, ${ }^{*}$ Kanako Watanabe, Airi Takizawa, Hikaru Shimizu, Takayuki Maruyama

Course of Applied Chemistry, Division of Chemistry and Materials, Faculty of Textile Science and Technology, Shinshu University, Ueda, Nagano 386-8567

* Corresponding author, Tel.: +81 268 5402; fax: +81 268 5391;
E-mail address jmotoyo @ shinshu-u.ac.jp

Keywords:

peroxyoxalate chemiluminescence

geometrical isomerization

stilbene

photochemistry without light

\begin{abstract}
The chemically-induced isomerization of stilbenes during the peroxyoxalate chemiluminescence (PO-CL) reactions was reinvestigated. The PO-CL reactions using bis(2,4,6-trichlorophenyl) oxalate in the presence of several stilbenes (type A reaction) produced cis-stilbenes in 0- $4 \%$ yields, which was dependent on the singlet excitation energy of the stilbenes. On the other hand, the PO-CL reactions of the oxalates, containing the stilbene moieties in the molecules (type B reaction), produced cis-stilbenes 0-9.3\% yields, some of which were much more effective than the type A reactions considering the amount of the oxalate moiety as the energy supplier.
\end{abstract}

Chemiluminescence reactions produce energy for the excitation of the fluorescent molecules to emit light, while the energy can be used for sensitization of the coexisting photochemically reactive molecules instead of the chemiluminescence. A few significant reports documented such a chemical sensitization called "photochemistry without light", ${ }^{1}$ in which some typical photoreactions were induced during the chemiluminescent reactions that included the thermal decomposition of the 1,2-dioxetanes, oxidation of the phthalhydrazides, ${ }^{2}$ and the peroxyoxalate chemiluminescence (CL) reactions. ${ }^{3}$ One of the representative examples is the cis-trans isomerization of stilbenes during the peroxyoxalate chemiluminescence (PO-CL) reaction ${ }^{3 a}$ instead of a light emission as shown in Scheme 1. Although the concept of "photochemistry without light" is very attractive from the viewpoint of the energy source for the photoreactions without irradiation by a UV lamp, less 
attention has been paid to such the systems and there have been only a few examples. ${ }^{2,3}$ As a part of our continuing study of the peroxyoxalate chemiluminescence, ${ }^{4}$ we revisited this interesting CL reaction accompanying the geometrical isomerization of stilbenes and investigated the two types of PO reactions without fluorophores, one of which is the PO reaction in the presence of various stilbenes (type A reaction) and the other which is that using the oxalates containing the stilbene unit in the oxalate molecules (type B reaction).

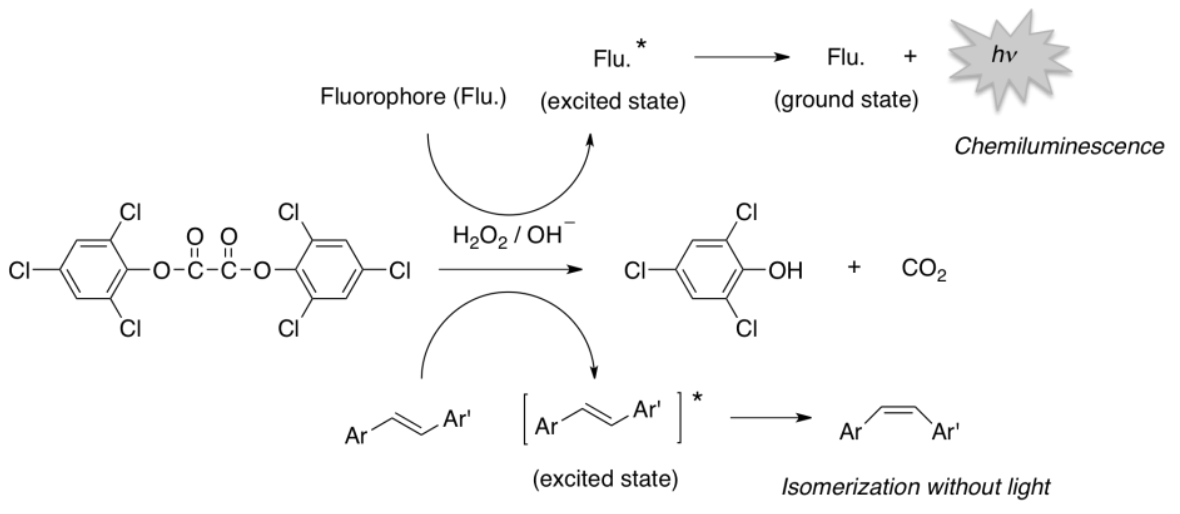

Scheme 1 Chemiluminescence and isomerization without light

To investigate the type A reactions, the trans-stilbenes (1a-h) bearing various substituents $(7.5 \mathrm{x}$ $10^{-4} \mathrm{M}$ in $\left.\mathrm{THF} / \mathrm{H}_{2} \mathrm{O}=3 / 1\right)$ were treated with bis(2,4,6-tricholorophenyl) oxalate (TCPO) (3.75 $\mathrm{x}$ $\left.10^{-2} \mathrm{M}\right)$ and hydrogen peroxide $\left(2.5 \times 10^{-2} \mathrm{M}\right)$ under alkaline conditions $\left(\mathrm{K}_{2} \mathrm{CO}_{3}, 2.5 \times 10^{-5} \mathrm{M}\right)$. After work-up the stilbenes were quantitatively obtained and no other product was detected in this reaction. The reactions were repeated at least three times for each stilbene and the ratios of the cisand trans-stilbenes were determined by their ${ }^{1} \mathrm{H}$ NMR spectra. The results are summarized in Table 1. Although the ratio varied below $10 \%$, some trans-stilbenes $(\mathbf{1 c}, \mathbf{1 d}, \mathbf{1 e}, \mathbf{1 g}$, and $\mathbf{1 h})$ isomerized to the cis-stilbenes during the peroxyoxalate (PO) reactions of TCPO, while three stilbenes $(\mathbf{1 a}, \mathbf{1 b}$, and 1f) did not isomerize at all.

To compare the isomerization efficiency for the above PO reactions to that for the photochemical reactions, the trans-stilbenes were treated in aqueous THF $\left(\mathrm{THF} / \mathrm{H}_{2} \mathrm{O}=3 / 1\right)$ by irradiation using a high pressure mercury lamp for $2 \mathrm{~min}$. and the ratios determined by ${ }^{1} \mathrm{H}$ NMR spectra are shown in Table 1. The tendency of the substituent-depending cis-isomer ratio in the chemiluminescent reactions was roughly similar to that in the direct photoisomerization as shown in Figure 1, and thus the peroxyoxalate chemiluminescent reaction provides the situation similar to the direct photoexcitation of the stilbenes. These ratios of the cis-stilbenes obtained in the present study are lower than that previously reported in which trans-4-methoxy-4'-nitrostilbene was treated with bis(2,4-dinitrophenyl) oxalate (DNPO) (5 equiv. to the stilbene) and hydrogen peroxide in dimethoxyethane under anhydrous conditions to afford a $9 \%$ yield of the cis-isomer as the maximum value. ${ }^{3 a}$ The lower ratios in the present study, in spite of the high amount of TCPO (50 equiv. to the stilbenes), would be due to the different reaction conditions, i.e., the reactions were 
carried out in aqueous media and the use of TCPO instead of more reactive DNPO. We examined the concentration effect under the conditions changing the ratios of stilbene/oxalate $(1 / 10,1 / 20$, 1/50) and found that the higher ratio than 1/50 gave no cis-isomer. In the type A reactions, $1 \mathrm{~g}$ with the cyano group was transformed into the cis-isomer the most effectively of all. This would be due to the lower singlet excitation energy of $\mathbf{1 g}$ than the others, because it showed the maximum absorption at $338 \mathrm{~nm}$ in the solvents the same as used for the reactions and the emission at $559 \mathrm{~nm}$, which was the longest wavelength of all except for $\mathbf{1 h}$ with the absorption and emission at $338 \mathrm{~nm}$ and $422 \mathrm{~nm}$, respectively. The difference in the isomerization ratio between $\mathbf{1 g}$ and $\mathbf{1 h}$ can be explained by the rapid loss of the excitation energy of $\mathbf{1 h}$, because the excited $\mathbf{1 h}$ decays faster than $\mathbf{1 g}$ due to the hydrogen bonding in the aqueous media due to the very weak emission of $\mathbf{1 h}$ in the aqueous media. ${ }^{6}$

Table 1 Isomerization of stilbenes (1a-i) in the PO reactions of TCPO (Type A reaction).

\begin{tabular}{|c|c|c|c|c|c|c|c|c|c|}
\hline \multirow[b]{2}{*}{ trans-stilbene } & \multirow[b]{2}{*}{$\mathrm{R}^{1}$} & \multirow[b]{2}{*}{$\mathrm{R}^{2}$} & \multirow[b]{2}{*}{$\mathrm{R}^{3}$} & \multicolumn{4}{|c|}{ cis-stilbene $(\%) b$} & \multirow{2}{*}{$\begin{array}{c}c \\
\text { Ratio of cis-isomer } \\
\text { in photoirradiation (\%) }\end{array}$} & \multirow{2}{*}{ Abs. (nm) ${ }^{a}$} \\
\hline & & & & Entry 1 & Entry 2 & Entry 3 & Average & & \\
\hline $1 a$ & $\mathrm{H}$ & $\mathrm{H}$ & $\mathrm{H}$ & 0 & 0 & 0 & 0 & 0 & 297 \\
\hline $1 \mathrm{~b}$ & $\mathrm{H}$ & $\mathrm{H}$ & $\mathrm{OMe}$ & 0 & 0 & 0 & 0 & 12.1 & 320 \\
\hline $1 \mathrm{c}$ & $\mathrm{OMe}$ & $\mathrm{H}$ & $\mathrm{OMe}$ & 1.6 & 0.8 & 1.2 & 1.2 & 10.3 & 323 \\
\hline $1 d$ & $\mathrm{OBu}$ & $\mathrm{H}$ & $\mathrm{OMe}$ & 0.8 & 0.6 & 0.6 & 0.7 & 29.7 & 328 \\
\hline $1 \mathrm{e}$ & ${ }^{t} \mathrm{Bu}$ & $\mathrm{H}$ & $\mathrm{OMe}$ & 0.5 & 0.4 & 0.8 & 0.6 & 11.7 & 322 \\
\hline $1 f$ & $\mathrm{H}$ & $\mathrm{Me}$ & $\mathrm{OMe}$ & 0 & 0 & 0 & 0 & 7.2 & 287 \\
\hline $1 \mathrm{~g}$ & $\mathrm{CN}$ & $\mathrm{H}$ & $\mathrm{OMe}$ & 7.9 & 7.9 & 6.2 & 7.3 & 46.1 & 338 \\
\hline $1 \mathrm{~h}$ & COOEt & $\mathrm{H}$ & $\mathrm{OMe}$ & 1.6 & 1.1 & 0.6 & 1.1 & 2.7 & 338 \\
\hline
\end{tabular}

${ }^{a}$ [stilbenes $\left.(1 \mathrm{a}-1 \mathrm{i})\right]=7.5 \times 10^{-3} \mathrm{M},[\mathrm{TCPO}]=3.75 \times 10^{-2} \mathrm{M},\left[\mathrm{H}_{2} \mathrm{O}_{2}\right]=2.5 \times 10^{-1} \mathrm{M},\left[\mathrm{K}_{2} \mathrm{CO}_{3}\right]=2.5 \times 10^{-5} \mathrm{M}$. ${ }^{b}$ Determined by ${ }^{1} \mathrm{H}$ NMR after the work-up.

${ }^{c}$ Direct photoisomerization of trans-stilbenes under irradiation by a high pressure mercury lamp for $2 \mathrm{~min}$.

in $\mathrm{THF} / \mathrm{H}_{2} \mathrm{O}_{2}$ (3/1). [trans-stilbene] $=1.0 \times 10^{-4} \mathrm{M}$

${ }^{d}$ Absorption with the longer wavelength of two large peaks around $300 \mathrm{~nm}$. 

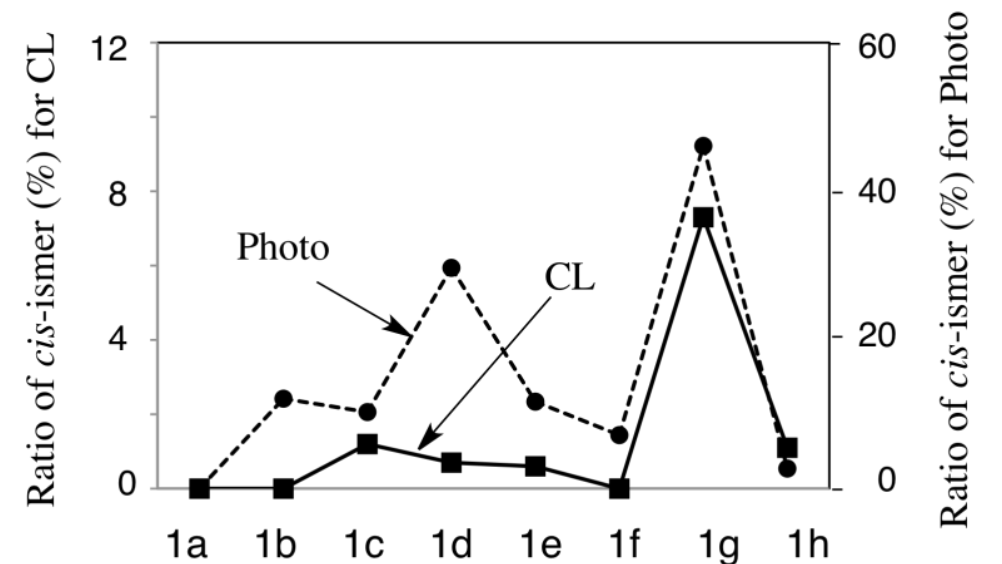

Figure 1. Ratios of cis-stilbenes (\%) for the chemiluminescent reaction (CL) and direct photoisomerization (Photo).

Next, for the type B reactions, the PO reactions of the oxalates $(\mathbf{2 b}, \mathbf{2 d}, \mathbf{2 e}, \mathbf{2} \mathbf{f}, \mathbf{2} \mathbf{g}$ and $\mathbf{2 h}),{ }^{4 b, 5}$ containing the stilbene moieties were reacted with aqueous hydrogen peroxide under weak alkaline conditions. After a work-up similar to the above type A reactions, the cis/trans ratios of the stilbenes were determined by their ${ }^{1} \mathrm{H}$ NMR spectra. As shown in Table 2, the ratios of the cis-stilbenes increased compared to the type A reactions except for $\mathbf{2 g}$ and $\mathbf{2 h}$. To explore the photochemical behavior of $2 \mathrm{~g}$ and $2 \mathrm{~h}$, we examined the photoirradiation of the corresponding phenolic stilbenes such as 4-cycno-4'-hydroxystilbene (3) and 4-carboethoxy-4'-hydroxystilbene (4) under the neutral and basic conditions. The cis-isomers were formed in $4.1 \%$ for 3 and $5.1 \%$ for $\mathbf{4}$, respectively, after $5 \mathrm{~min}$. irradiation under the neutral condition, and $32 \%$ for 3 under the basic condition. These results show that the cis-isomers formed during the type B reactions can exist in their forms under the reaction conditions and not isomerize to the trans-isomers. Considering the amount of the oxalate moiety as an energy supplier, the type B reactions are much more effective than the type A reactions except for the push--pull type stilbenes $2 \mathrm{~g}$ and $2 \mathrm{~h}$. In Figure 2 the ratios of the cis-isomers generated during the type $\mathrm{B}$ reaction and the photoirradiation are illustrated. The reason that $2 \mathrm{~g}$ and $2 \mathrm{~h}$ gave no cis-stilbenes might be due to the poor trans to cis isomerization of donor-acceptor type stilbenes in the protic solvents as previously reported. ${ }^{7}$ It is also noteworthy that when perylene was added as a fluorophore to the PO reactions of $\mathbf{2} \mathbf{d}$ and $\mathbf{2} \mathbf{f}$, no or less isomerization was observed due to the consumption of the excitation energy forming the excited perylene, namely, the ratios of the cis-stilbenes were reduced from $2.1 \%$ to $0 \%$ and from $9.3 \%$ to $3.8 \%$ for $2 \mathbf{d}$ and $\mathbf{2 f}$, respectively. 
Table 2 Peroxyoxalate reactions of the oxalates bearing the stilbene moiety (Type B reaction).

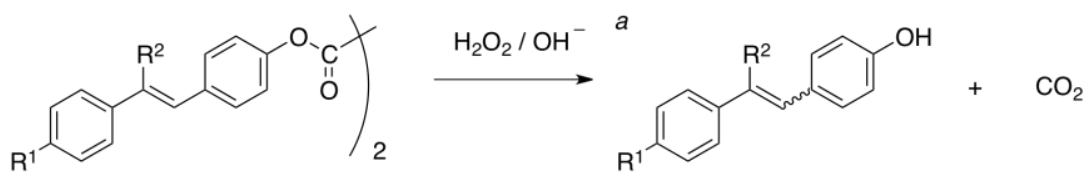

\begin{tabular}{|c|c|c|c|c|c|c|c|}
\hline \multirow[b]{2}{*}{ oxalate } & \multirow[b]{2}{*}{$\mathrm{R}^{1}$} & \multirow[b]{2}{*}{$\mathrm{R}^{2}$} & \multicolumn{4}{|c|}{ cis-stilbene (\%) $b$} & \multirow{2}{*}{$\begin{array}{c}\text { Ratio of cis-isomer } \\
\text { in photoirradiation of corresponding } \\
\text { phenolic stilbenes (\%) }\end{array}$} \\
\hline & & & Entry 1 & Entry 2 & Entry 3 & Average & \\
\hline $2 b$ & $\mathrm{H}$ & $\mathrm{H}$ & 7.3 & 5.9 & 4.8 & 6.0 & 0 \\
\hline $2 d$ & $\mathrm{OBu}$ & $\mathrm{H}$ & 2.2 & 2.2 & 1.8 & 2.1 & 14.2 \\
\hline $2 e$ & tert-Bu & $\mathrm{H}$ & 6.5 & 6.2 & 4.2 & 5.6 & 11.7 \\
\hline $2 f$ & $\mathrm{H}$ & $\mathrm{Me}$ & 8.8 & 10.0 & 8.9 & 9.3 & 3.0 \\
\hline $2 g$ & $\mathrm{CN}$ & $\mathrm{H}$ & 0 & 0 & 0 & 0 & 4.1 \\
\hline $2 \mathrm{~h}$ & COOEt & $\mathrm{H}$ & 0 & 0 & 0 & 0 & 5.1 \\
\hline
\end{tabular}

$a$ [oxalate $]=7.5 \times 10-2 \mathrm{M},[\mathrm{H} 2 \mathrm{O} 2]=2.5 \times 10-1 \mathrm{M},[\mathrm{K} 2 \mathrm{CO} 3]=2.5 \times 10-4 \mathrm{M}$ in THF/H2O2 (3/1).

${ }^{b}$ Determined by ${ }^{1} \mathrm{H}$ NMR after the work-up.

${ }^{c}$ Direct photoisomerization of trans-stilbenes under irradiation by a high pressure mercury lamp for $2 \mathrm{~min}$. in $\mathrm{THF} / \mathrm{H}_{2} \mathrm{O}_{2}(3 / 1)$. [trans-stilbene] $=1.0 \times 10^{-4} \mathrm{M}$.

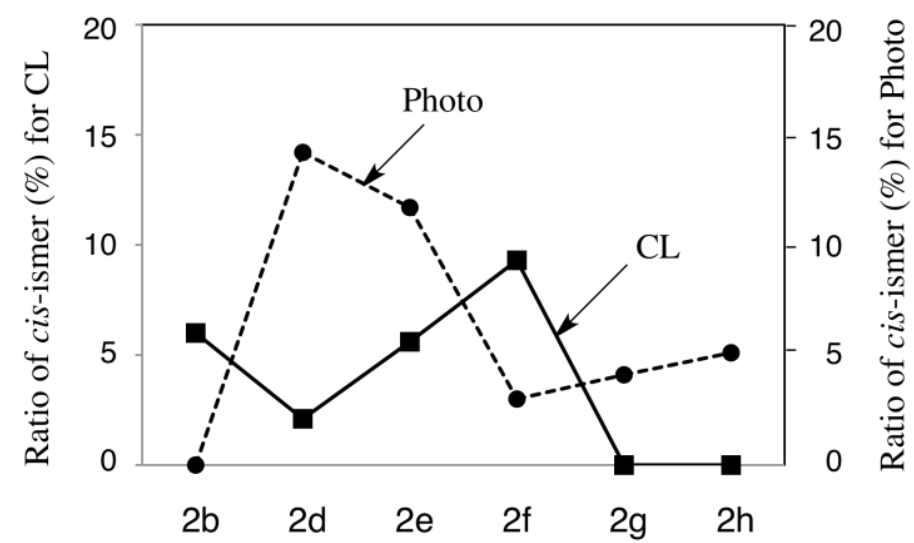

Figure 2. Ratios of cis-stilbenes (\%) for the chemiluminescent reaction (CL) and direct photoisomerization of teh corresponding phenolic stilbenes (Photo).

There is a remarkable difference in the isomerization efficiency between the type A and B reactions as described above. The PO-CL reaction is believed to involve the 1,2-dioxetanone bearing one stilbene moiety or the 1,2-dioxetanedione as the high-energy intermediates, ${ }^{4 d, 8}$ the former of which is the precursor of the latter and formed by the initial acyl substitution of the hydroperoxide anion to the oxalate followed by the intramolecular nucleophilic addition of the peroxide end, and the latter of which contains no stilbene moiety and is ready to decompose to two moles of carbon dioxide. The type $\mathrm{B}$ reactions provided the interesting result as mentioned above, namely, the appearance in Figure 2 shows an opposite tendency between two excitation ways. 
There might be an excitation process in the type B reactions different from the energy transfer as in the type A reaction. A plausible explanation is that an intramolecular charge transfer or an electron exchange process is involved in the type $\mathrm{B}$ reactions as can be seen in some bioluminescence ${ }^{9}$ or as proposed during the CIEEL process for the PO-CL, ${ }^{8,10}$ respectively. In this assumed mechanism the isomerization of the formed radical cations of the stilbenes might occur as shown in Scheme 2. ${ }^{11}$ The intramolecular charge transfer or an electron transfer would take place between the 1,2-dioxetanedione still bearing the stilbene moiety or the 1,2-dioxetanedione and the liberated stilbenes, once they are formed in the solvent cage. In contrast, the electron deficient cyano and carboethoxy groups of $\mathbf{2} \mathbf{g}$ and $\mathbf{2 h}$ prevented the electron transfer from the stilbene unit to the 1,2-dioxetane moiety, resulting in no isomerization.

The isomerization efficiency of this electron transfer system is comparable or higher comparing the fumaronitrile or 9,10-dicyanoanthracene sensitized isomerization of trans-stilbene whose $\Phi_{\mathrm{cs}}$ were reported to be $0.011-0.31,{ }^{9 a, b}$ because $\Phi_{c s}$ for $\mathbf{2 b}$ was calculated to be 0.24 from the equation, $\Phi_{P O-c s}=($ yield of cis-stilbene) $\mathrm{x}$ [initial trans-stilbene $] /\left([\right.$ oxalate $\left.] \times \Phi_{\text {trans } \rightarrow \text { cis }}\right)$ defined for the stilbene's trans-cis isomerization during the peroxyoxalate chemiluminescence reaction, using 0.50 for $\Phi_{\text {trans } \rightarrow \text { cis }}$ as the tentative value of trans-stilbene. ${ }^{7}$ However, this mechanism is based on a little evidence and more detailed study is necessary, which will make the peroxyoxalate chemiluminescence reaction clearer.
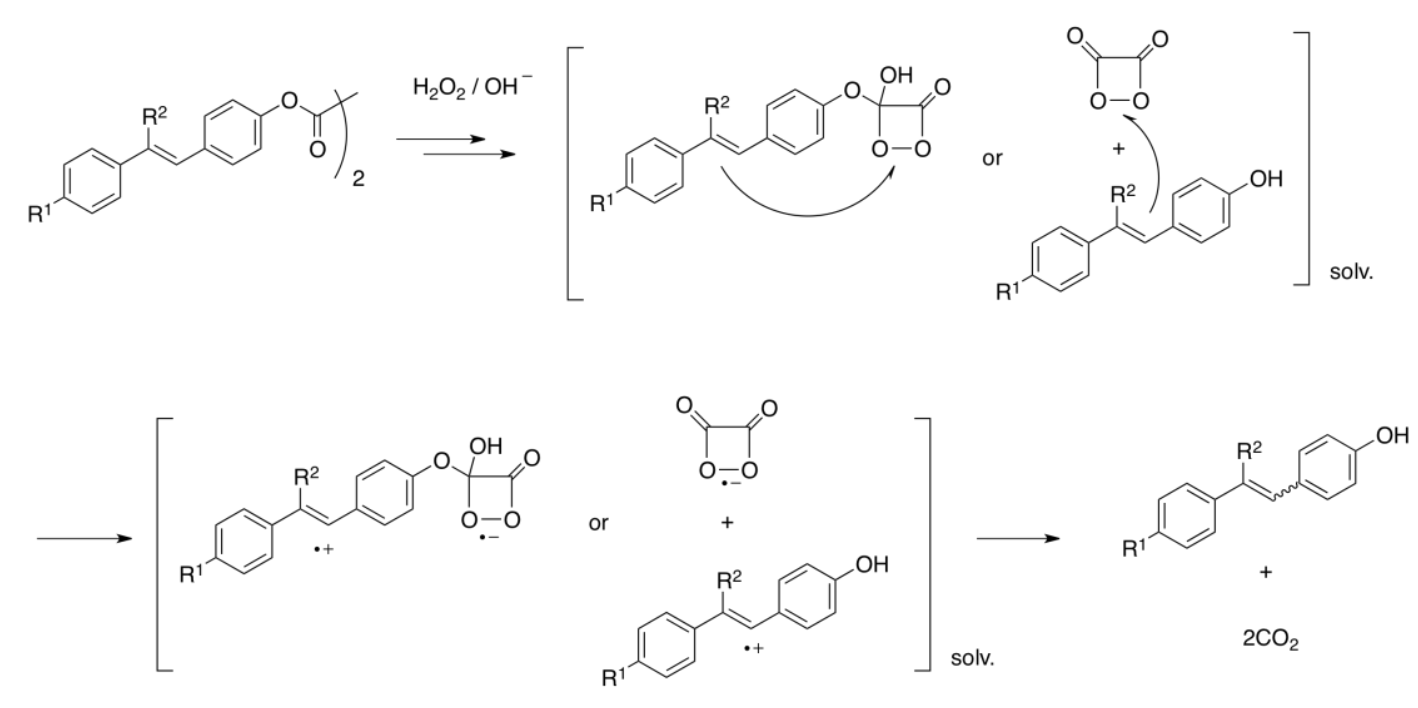

Scheme 2 A plausible electron transfer process for the chemically induced isomerization of the oxalates 2.

In conclusion, the chemically-induced geometrical isomerization of the stilbenes during the peroxyoxalate chemiluminescent reactions was investigated again and some new results were obtained. The isomerization efficiency was dependent upon the singlet excitation energy of the stilbenes for the type A reactions, while the isomerization occurred much more effectively in the type $\mathrm{B}$ reactions in which an intramolecular or quasi-intramolecular electron transfer might take place. 


\section{References and notes}

1. (a) Zimmerman, H. E.; Crumrine, D. S.; Doepp, D.; Huyffer, P. S. J. Am. Chem. Soc. 1969, 91, 434-445. (b) Zimmerman, H. E.; Keck, G. E.; Pflederer, J. L. J. Am. Chem. Soc. 1976, 98, 5574-5581.

2. White, E. H.; Wiecko, J.; Roswell, D. F. J. Am. Chem. Soc. 1969, 91, 5194-5196.

3. (a) Guesten, H.; Ullman, E. F. Chem. Commun. 1970, 28-29. (b) McCapra, F.; Perring, K.; Hart, R. J.; Hann, R. A. Tetrahedron Lett. 1981, 22, 5087-5090. (c) Goel, V. Oriental J. Chem. 2013, 29, 301-304.

4. (a) Motoyoshiya, J.; Sakai, N.; Imai, M.; Yamaguchi, R.; Koike, R.; Takaguchi, Y.;Aoyama, H. J. Org. Chem. 2002, 67, 7314-7318. (b) Koike, R.; Kato, Y.; Motoyoshiya, J.; Nishii, Y.; Aoyama, H. Luminescence, 2006, 21, 164-173. (c) Maruyama, T.; Fujie, Y.; Oya, N.; Hosaka, E.;Kanazawa, A.; Tanaka, Y.; Hattori, Y.; Motoyoshiya, J. Tetrahedron, 2011, 67, 6927-6933. (d) Maruyama, T.; Narita, S.; Motoyoshiya, J. J. Photochem. Photobiol. A: Chemistry, 2013, 252, 222-231.

5. Compound $2 \boldsymbol{b}$ : To a solution of $(E)$-4-hydroxystilbene $(0.37 \mathrm{~g}, 1.90 \mathrm{mmol})$ in benzene $(50 \mathrm{ml})$ and triethylamine $(0.23 \mathrm{~g}, 2.30 \mathrm{mmol})$ was added oxalyl chloride $(0.14 \mathrm{~g}, 1.10 \mathrm{mmol})$ dropwise under an argon atmosphere. After being stirred at room temperature for $2 \mathrm{~h}$, the precipitation was filtered and washed with THF. The washing containing the product was concentrated under a reduced pressure to give a white crystal, which was recrystallized from ethyl acetate. Yield: $84 \%$ (0.38 g); ${ }^{1} \mathrm{H}$ NMR (400 MHz, DMSO-d 6 ) $\delta$ 7.28-7.43 (m, 14H), 7.63 (d, 4H), $7.74(\mathrm{~d}, 4 \mathrm{H})$; HRMS (ESI): Calcd for $\mathrm{C}_{30} \mathrm{H}_{22} \mathrm{O}_{4} \mathrm{Na}\left([\mathrm{M}+\mathrm{Na}]^{+}\right)$: 469.1410, found 469.1411. Compound $2 d$ : This compound was prepared by the procedure as described above using (E)-butoxy-4'-hydoxystilbene $(0.8 \mathrm{~g}, 3.00 \mathrm{mmol})$, triethylamine $(0.30 \mathrm{~g}, 3.00 \mathrm{mmol})$, and oxalyl chloride $(0.19 \mathrm{~g}, 1.50 \mathrm{mmol})$ in THF $(50 \mathrm{ml})$. Yield $86 \%(0.76 \mathrm{~g}) ;{ }^{1} \mathrm{H}$ NMR $\left(400 \mathrm{MHz}, \mathrm{CDCl}_{3}\right)$ d $0.99(\mathrm{t}, 6 \mathrm{H}), 1.50(\mathrm{~m}, 4 \mathrm{H}), 1.78(\mathrm{~m}, 4 \mathrm{H}), 4.00(\mathrm{t}, 4 \mathrm{H}), 6.90(\mathrm{~d}, 4 \mathrm{H}), 6.97$ (d, 2H), $7.06(\mathrm{~d}, 2 \mathrm{H})$, $7.24(\mathrm{~d}, 4 \mathrm{H}), 7.44(\mathrm{~d}, 4 \mathrm{H}), 7.56(\mathrm{~d}, 4 \mathrm{H})$. HRMS (ESI): The molecular ion peak was not observed. Compound $2 \boldsymbol{e}$ : This compound was prepared by the procedure as described above using (E)-tert-butyl-4'-hydoxystilbene $(0.40 \mathrm{~g}, 1.60 \mathrm{mmol})$, triethylamine $(0.16 \mathrm{~g}, 1.6 \mathrm{mmol})$, and oxalyl chloride $(0.10 \mathrm{~g}, 0.79 \mathrm{mmol})$ in THF $(30 \mathrm{ml})$. Yield $84 \%(0.38 \mathrm{~g}) ;{ }^{1} \mathrm{H} \mathrm{NMR}(400 \mathrm{MHz}$, $\left.\mathrm{CDCl}_{3}\right) \delta 1.34(\mathrm{~s}, 18 \mathrm{H}), 7.06(\mathrm{~d}, 2 \mathrm{H}), 7.11(\mathrm{~d}, 2 \mathrm{H}), 7.26(\mathrm{~d}, 4 \mathrm{H}), 7.40(\mathrm{~d}, 4 \mathrm{H}), 7.47(\mathrm{~d}, 4 \mathrm{H}), 7.58$ (d, 4H); HRMS (ESI): Calcd for $\mathrm{C}_{38} \mathrm{H}_{38} \mathrm{O}_{4} \mathrm{Na}\left([\mathrm{M}+\mathrm{Na}]^{+}\right)$: 581.2662, found 581.2664. Compound $2 f$ : This compound was prepared by the procedure as described above using (E)-1-(4'-hydoroxyphenyl)-2-phenylpropene $(0.30 \mathrm{~g}, 1.30 \mathrm{mmol})$, triethylamine $(0.16 \mathrm{~g}, 1.60$ 
mmol), and oxalyl chloride $(0.10 \mathrm{~g}, 0.80 \mathrm{mmol})$ in benzene $(10 \mathrm{ml})$. Yield $80 \%(0.25 \mathrm{~g}) ;{ }^{1} \mathrm{H}$ NMR (400 MHz, $\left.\mathrm{CDCl}_{3}\right) \delta 2.30$ (brs, 6H), $6.82(\mathrm{~s}, 2 \mathrm{H}), 7.28-7.32(\mathrm{~m}, 6 \mathrm{H}), 7.38(\mathrm{t}, 4 \mathrm{H}), 7.44(\mathrm{~d}$, $4 \mathrm{H}), 7.53$ (d, 4H); HRMS (ESI): Calcd for $\mathrm{C}_{32} \mathrm{H}_{26} \mathrm{O}_{4} \mathrm{Na}\left([\mathrm{M}+\mathrm{Na}]^{+}\right): 497.1723$, found 497.1724. Compound 2g: This compound was prepared according to the established procedure. $4 \mathrm{~b}$ Compound $2 \boldsymbol{h}$ : This compound was prepared by the procedure as described above using (E)-4-carbethoxy-4'-hydroxystilbene $(0.80 \mathrm{~g}, 3.00 \mathrm{mmol})$, triethylamine $(0.30 \mathrm{~g}, 3.00 \mathrm{mmol})$, and oxalyl chloride $(0.19 \mathrm{~g}, 1.50 \mathrm{mmol})$ in THF $(30 \mathrm{ml})$. Yield $72 \%(0.64 \mathrm{~g}) ;{ }^{1} \mathrm{H}$ NMR $(400 \mathrm{MHz}$, $\left.\mathrm{CDCl}_{3}\right) \delta 1.40(\mathrm{t}, 6 \mathrm{H}), 4.38(\mathrm{q}, 4 \mathrm{H}), 6.84(\mathrm{~d}, 1 \mathrm{H}), 7.13(\mathrm{~d}, 2 \mathrm{H}), 7.22(\mathrm{~d}, 2 \mathrm{H}), 7.30(\mathrm{~d}, 3 \mathrm{H}), 7.43(\mathrm{~d}$, 1H), $7.53(\mathrm{~d}, 1 \mathrm{H}), 7.59(\mathrm{~m}, 6 \mathrm{H}), 8.01(\mathrm{~d}, 1 \mathrm{H}), 8.05(\mathrm{~d}, 3 \mathrm{H})$. HRMS (ESI): Not measured because of thermal lability.

6. Nakatsuji, S.; Matsuda, K.; Uesugi, Y.; Nakashima, K.; Akiyama, S.; Katzer, G.; Fabian, W. J. Chem. Soc. Perkin Trans. 2, 1991, 861-867.

7. Gegiou, D.; Muszkat, K. A.; Fischer, E. J. Am. Chem. Soc. 1968, 90, 3907-3918.

8. Ciscato, L. F. M. L.; Augusto, F. A.; Weiss, D.; Bartoloni, F. H.; Albrecht, S.;Brandl,H.; Zimmermann, T.; Baader, W. Arkivoc, 2012, 391-430.

9. Koo, J. -Y.; Schmidt, S. P.; Schuster, D. B. Proc. Natl. Acad. Sci. U. S. A. 1978, 75, 30-33.

10. Stevani, C. V.; Silva, S. M.; Baader, W. Eur. J. Org. Chem. 2000, 4037-4046.

11. (a) Hub, W.; Klueter, U.; Schneider, S.; Doerr, F. J. Phys. Chem. 1984, 88, 2308-2315. (b) Lewis, F. D.; Petisce, J. R.; Oxman, J. D.; Nerpras, M. J. J. Am. Chem. Soc. 1985, 107, 203-207. 